\title{
Estética da periferia: uma reflexão sobre o contexto político e social
}

\author{
Lilian Fontes Moreira*
}

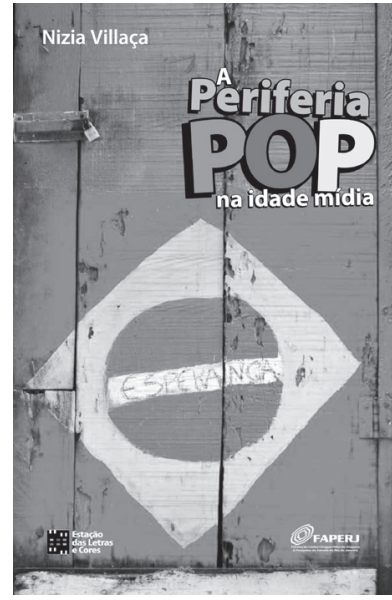

VILLAÇA, Nizia. A periferia pop na idade mídia. São Paulo: Estação das Letras e Cores, 2012. 175 p.

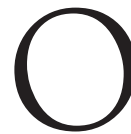

termo "cidade partida", disseminado pelo livro de Zuenir Ventura lançado em 1994, calcado numa sociologia de espaços urbanos diferenciados pela estrutura socioeconômica, há tempos vem tomando nova roupagem. $\mathrm{O}$ crescimento das favelas do Rio de Janeiro, o acirramento da violência, veio provocar a revisão desses conceitos sobre a cidade. A dicotomia "morro x asfalto" usada para designar a relação favela e zonas urbanizadas foi substituída pelos termos centro e periferia, uma tentativa de nomeação mais ampla, incluindo comunidades diversas com suas respectivas manifestações culturais.

$\mathrm{Na}$ necessidade de encarar essa realidade, surgem, então, movimentos de integração social aceitando e absorvendo a multiplicidade de estéticas e comportamentos concernentes as diversas camadas sociais. Assim, o novo livro de Nizia Villaça, "A periferia pop na Idade Mídia", tem a preocupação de refletir sobre a noção de peri-

\footnotetext{
* Jornalista, escritora, doutora em Comunicação e Cultura pelo Programa de Pós-Graduação da Escola de Comunicação da Universidade Federal do Rio de Janeiro (UFRJ). Rio de Janeiro-RJ, Brasil. Pós-doutorado pela UFRJ, com apoio da FAPERJ. E-mail: lilianfontes20@gmail.com
} 
feria tanto no âmbito nacional como no âmbito latino-americano.

Nesta obra, a preocupação da autora é pensar sobre o contexto político das negociações e regulações, analisando a produção e recepção de produtos na periferia, as negociações com o centro, permeadas de valores, crenças, normas e interpretações. Calcada no projeto sobre "Rio de Janeiro, moda, e periferia", com apoio da FAPERJ, Nizia Villaça, reuniu um amplo material baseado em pesquisa na internet, visitas a comunidades, aulas em escolas de segundo grau utilizando material que incluiu filmes como "Sonhos roubados", de Sandra Werneck e "5 x Favela, agora por nós mesmos”, de Cacá Diégues, contando ainda com a contribuição de um mestrando habitante da Cidade Alta e uma doutoranda atuando nas políticas públicas da Secretaria de Governo do Rio de Janeiro.

Observando que muitos dos conceitos utilizados pela mídia como por alguns textos acadêmicos e de produção cultural terminam por não estabelecer uma conexão entre teoria e a prática, o foco de Nizia foi pesquisar as estratégias de abordagem e o processo de interação entre pesquisador, grupo social abordado e público em geral, ligando comunicação e cultura no âmbito das dinâmicas de desenvolvimento, como aponta Martín-Barbero em seu artigo "La comunicación y la cultura en la cooperacíon al desarrollo".

Num enfoque de contextualização, a obra indica que, a partir de meados de 1990, a periferia passa a ser valorizada simbolicamente e as classes média e alta se deixam atrair pela estética periférica. Nesse processo, a autora chama a atenção para os procedimentos de espetacularização, tanto na escala global, quanto na local, visando não ao habitante local, mas sim, ao turista internacional. Sua preocupação é apontar para a verificação das estratégias de visibilidade que se apropriam da cultura popular visando os padrões turísticos universais.

Lembrando Michel de Certeau, em "La culture au pluriel", no qual divaga sobre os conceitos no campo da diversidade cultural e as posições dos estados e instituições internacionais com suas políticas públicas, Nizia analisa a situação do Brasil nesse universo, lembrando que nas duas últimas décadas, houve um movimento para o reconhecimento das desigualdades culturais e socioeconômicas. Em relação ao Rio de Janeiro, a autora aponta a necessidade de haver uma avaliação mais profunda quanto às 
questões ligadas à homogeneidade e diferença baseada nas peculiaridades da cidade, afirmando que os pesquisadores são obrigados a pensar o espaço fora das categorias estabelecidas como, urbano versus rural, centro versus periferia. Baseando-se em estudos de Kathryn Woodward e da antropóloga Mary Douglas, Nizia afirma: "É preciso pensar como a identidade e a diferença são produzidas, pensar a multiplicidade e não apenas a diversidade" (p.102).

Refletindo sobre a estética pop que viria representar as diversas dimensões que caracteriza produtos, pessoas, coisas, eventos, a autora chama a atenção para o fato de que a "popficação" periférica tanto pode implicar uma ótica inclusiva como também uma ótica de discriminação, dependendo do olhar que a mídia lhe dirige. O fundamental, portanto, é aprofundar as questões ligadas à produção do discurso midiático. "O que chama a atenção no contemporâneo é que as culturas urbanas, progressivamente, perdem sua fisicidade geográfica, sua estabilidade, e passam a serem visivelmente elementos coo estruturantes dos processos de subjetivação, contribuindo para isso toda a publicidade midiática" (p.47), diz a autora.

Dessa maneira, o que temos no livro é um amplo estudo que engloba ainda temas como vivências urbanas (tomando como base a complexidade da relação corpo, cidade, identidade e diferença), políticas públicas, a questão favela propriamente dita (sua remoção, urbanização com a discussão dos conceitos de hibridez e subalternidade) além da dinâmica do corpo, moda e espaço. No final, destaque para a experiência junto à comunidade do Terreirão, periferia no Recreio dos Bandeirantes, na cidade do Rio de Janeiro, acompanhando as oficinas lá realizadas, sobre moda e design, utilizando material da região.

O livro se encerra com comentários e análises sobre a estrutura da comunicação dedicada à favela e à periferia, nos apresentando, então, uma enorme contribuição para se pensar os movimentos de incorporação social na Idade Mídia. 